\title{
Quality Nursing Care Versus Patient Satisfaction And Nurses Job Satisfaction In Zagazig University Hospitals
}

\section{Manal Fauzy Eldaly :}

Quality coordinator, Ministry Of Health,

\section{Eglal Ahmed Abd-Elwahab}

Assistant Prof. of Nursing administration, Cairo University,

\section{Maha Abdeen Abdeen:}

Lecture of Nursing Administration, Faculty of Nursing, Zagazig University

\begin{abstract}
:
Quality of care is a right of all patients and responsibility of all nurses who deliver it. Quality is the effect of care on the individual and population. Effective improvement in quality of nursing performance should be reflected in better health, patient satisfaction and nurses' satisfaction. The aim of this study aimed to assess the level of job satisfaction among nurses, measure quality of work performed by study nurses and assess the patient satisfaction related to nursing care performance. Setting: the study carried out at new surgical hospital that affiliated to Zagazig university hospitals. The study sample: included (47) nurses and (1053) patients from different surgical wards at zagazig university hospital. Tools: three tools used to collect the necessary data; the questionnaire sheet to assess nurses job satisfaction factors, a patient' satisfaction questionnaire sheet and nurses' observational checklist to assess nurses performance for patient care. The results revealed that, most of nurses at surgical wards in new surgical hospital were satisfied in many factors when had the highest mean scores in relation to Salary, administration and management, work environment, relation at work, recognition, system of work, progress at work and work responsibilities factors. However, in relation to observed quality of nurses' performance the majority of nurses had an acceptable level in their practice on maintaining the patient rights factors, maintaining the elimination factors in the first and second 24 hours of
\end{abstract}


postoperative care. While, there were statistical significant relation between patient's education and their satisfaction with nurses' performance quality. Therefore, according to findings .Recommended that, developing a standard for surgical nursing care on Zagazig University Hospitals and it should be communicated to all healthcare providers to improve quality of care provided to patients, as reference for practice management and controlling Keys words: quality nursing care, patient satisfaction, nurses' satisfaction.

\section{Introduction}

Quality of care emerged as a major issue in health care and it will continue to be a crucial issue as the healthcare reform implemented (Zerwek and Claborn, 2006). Quality can be defined as the degree to which consumer progress toward desired outcomes which established with guidance and support of healthcare providers (Suganthi \& Samuel, 2005). In addition, Evan and Lindsay (2005) defined quality as an overall experience and satisfaction of patient with nursing services from the moment of admission until discharge.

Nursing service quality refers to an overall judgment of a particular service, and there is a difference between expected quality and perceived quality. Moreover, the nursing service quality is a critical component of patients' perceptions of value that determines their satisfaction (Chunlaka, 2010).

Satisfaction with healthcare service is a topic of wide interest to both people who work in organizations and people who study it because it is important for all health professionals (Mc-Laughlin and Kaluzuy , 2007 ) .

Patient-centered care has become a major concern of health care providers, patient satisfaction with nursing care became a pivotal indicator of the quality of care provided in hospitals, and helping patients to adjust their expectations of a cure is important step in reducing the severity of the condition. However 6 it is important to provide patients with hope (Peterson, 2005).

Therefore, consumer and patient's satisfaction has been used as index for 
measuring quality of nursing care by using the consumer or patient satisfaction questionnaire as a measurement tool reflects what the patient thinks about the quality of nursing care they received and focus on patient's experiences about their total hospital stay (Kudo et al., 2006) .

Moreover, in the recent years a high quality of care is the right of all patients, which require increasing the level of quality in Egypt. A little concern started to be considered, there must be a large step to be moved directly toward quality that meet or exceed customers expectations which is the ultimate goal of many healthcare organization (American Hospital Association., 2010) .

Furthermore, job satisfaction has become a key concept within nursing work for the research in recent years. This is largely due to the view that nurses' job satisfaction has a wide spread and significant implications for nurses, patient, hospitals and the profession (Torninsk et al., 2005).

While, Belegan (2006) believed largely that job satisfaction linked with a number of positive outcomes, higher perceived quality life and less workrelated stress. Chu \& Lee (2010) found by recent studies that nurses were most stressed when their ability to practice quality nursing care was impeded. On the other word, inappropriate care provided to patients contribute to high level of job stress and feelings of frustration, inadequacy, self- doubt , lowered self- esteem, irritability, hopelessness, depression and burnout (Dorothy \& Judith, 2010 ) .

Therefore, to produce effective and continuing quality improvement there should be a great interest to healthcare providers; satisfaction with their work and belonging to work target, to achieve higher level of quality care and higher level of their job satisfaction

\section{( Blumenthal , 2005 ) .}

\section{Aim of the study:}

\section{The study aimed to:}

Assess the quality of nursing care versus patient satisfaction and nurses' job satisfaction in Zagazig University Hospitals.

\section{Subject and methods:}

The research design: 


\section{Tanta Scientific Nursing Journal}

A descriptive design was used.

\section{Research setting:}

This study was conducted in surgical wards of new surgical hospital which affiliated to Zagazig University Hospitals.

\section{Subjects of the study:}

The study sample included two groups; namely staff nurses and patients.

The nurses group consisted of a convenience sample of all nurses available in the above mentioned setting who accepted to participate in the study. Nurses involved in the study had more than one year of experience. The total number of nurses meeting this criteria were 47 out of 50 nurses; because two nurses refused to participate in the study and one of them didn't return the questionnaire .As regards to their qualification ; all nurses had a nursing diploma .The patients group; all patients who were available and admitted to hospital who their age group ranged from one month to 78 years, fully conscious, with varied duration of hospitalization , all types of operation, with different educational levels .The total sample was (1052) patients admitted to surgical units at New Surgical Hospital from February to the end of September 2007 are included in the study .

\section{Tools for data collection:}

Three different tools were used for data collection in this study; the first tool is the questionnaire sheet for nurses' satisfaction, the second tool is the observation checklist of nurses' quality of performance, the third tool is the patient satisfaction questionnaire sheet.

\section{The first tool :Nurses' Satisfaction}

\section{Questionnaire:}

The first part; entails the demographic data such as age, qualification, years of experience, marital status, nursing care assignment method and shift pattern. The Second part was to assess nurses' satisfaction factors .It was developed based on the related literature (Mohamed, 2005 and El- Said, 2005 El- said, 2002 , Abd- Rabou, 2002) where the items were grouped under the following dimensions: salary factors (13) items, administration and work system factors (24) items, Work environment factors (10) items, leadership and supervision factors (17) items, relation at work factor (10) items, recognition from other (8) items, progress and work 


\section{Tanta Scientific Nursing Journal}

promotion factors (9) items, work itself factors (6) items, job achievement factors (7) items, work responsibility (12) items . The scoring systems were on bases of (yes, sometimes and no). Yes scored (two points, sometimes (one point) and no scored (zero). Then the nurses responses about job satisfaction factors were categorized into three level of scores which are; satisfied for $(65 \%)$ or more, to some extent from $(60-65)$ and not satisfied which less than (60\%).

The second tool: The observation checklist for quality of nurses' performance which developed based on review of related literature (Abd- Rabou , 2002, Abdeen , 2001, Said , 2000) as well as from previous experience with nurses in clinical setting . Its purpose was to assess quality of nurses' performance in the New Surgical Hospital. The first part includes the demographic characteristics of nurses. The second part of the observation checklist categorized under (8) main dimensions which include ; the admission procedures (10) items , patient rights factors (10) items , assessment of psychological condition (3) items, health education to patient(5) items, pre- and post -operative care which divided into (A) pre- operative care(72) items, ( B ) post - operative care ( first 24 hours after operation ) which included (62) items and (C) postoperative care (after 24 hours) which included(78), the general factors included; communication factors(14) items, documentation factors(4), and professionalism factors (10). The scoring system; responses could be done; either correctly (two points) or not correctly (scored one point) or not done (scored zero point). There are three observations done for each nurse in surgical ward where each observation taking from two to three hours. Then, the total number of each response is summed and so on for the two other responses (done; correctly or not correctly and not done). After ending the recording process for all observation checklist reposes the maximum scores, mean and standard deviation were calculated for quality of nurses performance factors, the range rates for all factors. Then, the $\mathrm{p}-$ value were calculated between the observed quality of nurses performance and the nurses' age and experience for statistical 


\section{Tanta Scientific Nursing Journal}

testing.

\section{The third tool ; Patients' Satisfaction}

Questionnaire:

used as a components of quality of nursing care. It was developed based on related literature review (Ibrahim, 1998, Abd- Rabuo, 2002 and Gad, 2002). Its purpose was to investigate the patient' satisfaction level as indicator of quality of nursing performance.

The first part entails the demographic data about patients such as age, sex, marital status, education, length of stay and frequency of admission.

The second part composed of questions related to elements of : the surrounding environment factors (6) items, patient rights factors (6) items, health education factors(5) items, nursing performance (8) items, social relation factors (5) items, Psychological condition and patient safety factors (74) items . The scoring system is on the basis of (yes and no). Yes were scored (one point) and no were scored (zero).

\section{Pilot Study:}

A pilot study was conducted to assess the tools clarity, to identify the obstacles, applicability and test it. It has served in estimating the time needed for filling the forms that ranged from 25- 40 minutes. Regarding the observation checklist; (5) nurses are selected randomly from the surgical wards in the New Surgical Hospital and observed to assess the applicability of the observation sheet.

\section{Field Work:}

This study was carried out during the period between February 2007 to the end of February 2008 . The investigator met the respondents individually during the three shifts to distribute the questionnaire or making the observations. During these meetings, the investigators explained the purpose of the study, and assured to respondents the anonymity of answers and that information will be used only for scientific research and will be confidential.

\section{Administrative Design:}

Formal approval was obtained through official letters sent to directors of medical and nursing departments at Zagazig University Hospitals explaining the aim of the study and assuring confidently of informate and seeking their permission

\section{Statistical Design:}

Data entry was done using computer and 


\section{Tanta Scientific Nursing Journal}

statistical analysis was done using microstate statistical soft- package. Data were presented by using different statistic techniques for data analysis as following: (1) Descriptive statistics in the form of frequencies and percentage.

Quantitative variable were compared by using: Standard deviation, which is the measure of standard deviation .Multiple

Table (1) Describe the sociodemographic characteristics of nurses in the study sample. This table indicate that, less than half ( $46.8 \%$ ) of study subjects were in the age group ranged from ( 21-30) years .While, the least percent

$(12.8 \%)$ of study subjects were in the age group more than 30 years. According to qualification the table shows that, all the staff nurses had diploma nurse (100\%). In addition, regarding to years of experience the highest percent $(80.9 \%)$ had five years or less. While, the least percent $(4.3 \%)$ had (11-15) years of experience in nursing. In relation to marital status of nurses, all of staff nurses had married (100\%). Regarding nursing care assignment methods this table indicates that, the majority of nurses $(87.1 \%)$ using comparison test, used for paired comparison.

Pearson correlation coefficient indicates the degree and direction of relationship between two variables (correlation between observed satisfaction factors total scores and staff nurse's performance).

\section{$\underline{\text { Results: }}$}

the functional method. However, most of nurses $(70.2 \%)$ worked in rotating shift.

Table (2) : Demonstrates that, nurses' satisfaction scores have been categorized into " satisfied " with a score $60 \%$ or more and " dissatisfied " with scores less than $60 \%$. The table clarifies that, nurses were dissatisfied in leadership and supervision factors and work promotion factors of nurses' satisfaction factors; The mean percent ( $59.4 \%$ and $58.9 \%$ ). While the nurses had the highest percent and be satisfied in the salary, administration and management, work environment, relation at work, recognition, system of work, progress at work and work responsibilities factors.

Table ( 3 ) : Clarifies that, there was a negative correlation between nurses' age and their observed quality of performance 


\section{Tanta Scientific Nursing Journal}

. But, this correlation was not statistically significant $(\mathrm{P}>0.05)$.

Table ( 4 ) : Shows that, there was a negative correlation between nurses' experience and their observed quality of performance . But, this correlation was not statistically significant ( $\mathrm{P}>0.05$ ).

Table (5): shows the distribution of patient according to socio- demographic characteristics. This table indicates that, more than half ( $58.6 \%$ ) of study subjects were in the department (C) . According to patients' age, the age group ranged from one month to 78 years. However, regarding to marital status of study subjects, around half of patients (52.4\%) were married. As regard to patients' gender more than two third (64.7 $\%$ were female. According to educational level of patients, the highest percentage $(38.1 \%)$ were for patients who able to read and write. Regarding to patients' types of surgery; about half (48.6 $\%$ ) of study subjects had major surgery. However, the length of stay (hospitalization period) ranged from (147) days and the majority of patients $(91.6 \%)$ had the first admission to hospital.
Table (6): describe the relation between education, diagnoses and patients' satisfaction factors. There were highly statistical significant differences between education, diagnoses and patients' satisfaction factors.

Table (7) clarifies the correlation matrix among scores of patient satisfaction factors. As shown in table, there was highly statistically significant negative correlation in the environmental, Patient rights and performance factors of patient satisfaction $(p<0.001)$.While, there was no statistical significant difference in the patient health education, social relation and patient safety and psychological factors. 
Table (1) The percentage distribution of the study group according to their demographic characteristics $(n=47)$.

\begin{tabular}{|c|c|c|}
\hline Characteristics & & \\
\hline & NO. & $\%$ \\
\hline$*$ Age $:-\leq 20$ & 19 & 40.4 \\
\hline$-\overline{21}-30$ & 22 & 46.8 \\
\hline$->30$ & 6 & 12.8 \\
\hline * Qualification :-Diploma : & 47 & 100.0 \\
\hline *Experience (Years) $\quad-\leq 5$ & 38 & 80.9 \\
\hline$-6-10$ & 7 & 14.9 \\
\hline$-11-15$ & 2 & 4.3 \\
\hline *Marital status: - Single : & 0 & 0 \\
\hline & 47 & 100.0 \\
\hline *Nursing care assignment methods: & 6 & 12.8 \\
\hline - Functional method: & 41 & 87.1 \\
\hline *Shift pattern : - Fixed shift & 14 & 29.8 \\
\hline$-R$ & 33 & 70.2 \\
\hline
\end{tabular}

Table ( 2 ) : Level of nurses' satisfaction scores among the study subjects according to their perception $(n=47)$.

\begin{tabular}{|l|c|c|c|}
\hline \multicolumn{1}{|c|}{ Nurses satisfaction factors: } & Max. Scores & Total Mean & $\begin{array}{c}\text { Mean } \\
(\%)\end{array}$ \\
\hline 1- Salaries . & 26 & 15.6 & 60 \\
\hline $\begin{array}{l}\text { 2- Administration and } \\
\text { management . }\end{array}$ & 48 & 28.8 & 60 \\
\hline 3- Work environment . & 20 & 12 & 60 \\
\hline 4- Leadership and supervision . & 34 & 20.2 & 59.4 \\
\hline 5- Relation at work & 20 & 12 & 60 \\
\hline $\begin{array}{l}\text { 6- Recognition } \\
\text { (appreciation ) }\end{array}$ & 16 & 9.6 & 60 \\
\hline 7- Work promotion . & 18 & 10.6 & 58.9 \\
\hline 8- System of work . & 12 & 7.2 & 60 \\
\hline 9- progress at work . & 14 & 8.4 & 60 \\
\hline 10- Work responsibilities & 24 & 14.4 & 60 \\
\hline
\end{tabular}

Table ( 3 ) : Correlation between the nurses' age and observed quality of nurses performance factors in New Surgical Hospital $(n=47)$.

\begin{tabular}{|l|c|cc|}
\hline The quality factors & $\mathbf{r}$ & \multicolumn{2}{|c|}{ P } \\
\hline $\begin{array}{l}\text { 1. Assessment of patient condition } \\
\text { at admission : }\end{array}$ & -0.19 & $>0.05$ & ( NS ) \\
\hline 2. Pre- operative care factors : & -0.16 & $>0.05$ & ( NS ) \\
\hline $\begin{array}{l}\text { 3.Post- operative care factors ( first } \\
\text { 24 hours ) }\end{array}$ & -0.09 & $>0.05$ & ( NS ) \\
\hline 4. Post- operative care factors ( & -0.04 & $>0.05 \quad$ ( NS ) \\
\hline
\end{tabular}




\begin{tabular}{|c|c|c|}
\hline second 24 hours ): & & \\
\hline 5. Communication : & -0.21 & $>0.05$ \\
\hline 6. Documentation : & -0.07 & $>0.05$ \\
\hline 7. Professionalism : & -0.1 & $>0.05$ \\
\hline
\end{tabular}

Table (4) : Correlation between the nurses' experience and observed quality of nurses performance factors in New Surgical Hospital $(n=47)$.

\begin{tabular}{|l|c|cc|}
\hline The quality factors & r & \multicolumn{2}{|c|}{ P } \\
\hline $\begin{array}{l}\text { 1. Assessment of patient } \\
\text { condition at admission : }\end{array}$ & -0.1 & $>0.05$ & ( NS ) \\
\hline $\begin{array}{l}\text { 2. Pre- operative care } \\
\text { factors : }\end{array}$ & -0.12 & $>0.05$ & ( NS ) \\
\hline $\begin{array}{l}\text { 3.Post- operative care } \\
\text { factors ( first 24 hours ) }\end{array}$ & -0.19 & $>0.05 \quad$ ( NS ) \\
\hline $\begin{array}{l}\text { 4. Post- operative care } \\
\text { factors ( second 24 hours ): }\end{array}$ & -0.06 & $>0.05$ & ( NS ) \\
\hline 5. Communication : & -0.09 & $>0.05$ & ( NS ) \\
\hline 6. Documentation : & -0.13 & $>0.05$ & ( NS ) \\
\hline 7. Professionalism : & -0.18 & & \\
\hline
\end{tabular}

Table ( 5) : The demographic characteristics of patients in New Surgical Hospital $(n=1052)$ :

\begin{tabular}{|c|c|c|}
\hline Characteristics & NO. & $\%$ \\
\hline Department :-Ward A : & 143 & 13.6 \\
\hline -Ward B : & 293 & 27.9 \\
\hline - Ward C: & 616 & 58.6 \\
\hline $\begin{array}{ll}\text { Age }: & - \\
& (\bar{X} \pm \text { SD })\end{array}$ & $30.4 \pm 18.1$ & (Range) $(0.1-78)$ \\
\hline Marital status : -Married: & 551 & 52.4 \\
\hline- Single & 501 & 47.6 \\
\hline Gender : & 371 & 33.3 \\
\hline * Female & 681 & 64.7 \\
\hline Education level : - Illiterate & 210 & 20.0 \\
\hline -Read/ write & 401 & 38.1 \\
\hline -Secondary & 193 & 18.3 \\
\hline - High education & 248 & 23.6 \\
\hline Types of surgery $: *$ Major & 511 & 48.6 \\
\hline$*$ Moderate & 108 & 10.4 \\
\hline * Minor & 433 & 41.2 \\
\hline Length of stay : & $30.2 \pm 8.5$ & $(1-47)$ \\
\hline $\begin{array}{l}\text { No. of admission: } \\
\text { first admission: }\end{array}$ & 964 & 91.6 \\
\hline * Second admission & 88 & 8.4 \\
\hline
\end{tabular}


Table (6): The relation between patient characteristics and patients' satisfaction factors in New Surgical Hospital at Zagazig university Hospitals

( $N$ = 1052):

\begin{tabular}{|c|c|c|c|c|c|}
\hline The factors & $\begin{array}{l}\text { Illiterate, } \\
\text { read }\end{array}$ & $\begin{array}{l}\text { SEC. } \\
\text { education }\end{array}$ & $\begin{array}{l}\text { High } \\
\text { education }\end{array}$ & \multirow[t]{2}{*}{$\mathbf{F}$} & \multirow[t]{2}{*}{$\mathbf{P}$} \\
\hline \multirow[b]{2}{*}{ Education : } & $\overline{\mathrm{X}} \pm \mathrm{SD}$ & $\bar{X} \pm \mathbf{S D}$ & $\bar{X} \pm$ SD & & \\
\hline & $\begin{array}{l}21.9+2.4 \\
(15-28)\end{array}$ & $\begin{array}{l}21.3+2.2 \\
(15-27)\end{array}$ & $\begin{array}{l}22.2 \pm 1.9 \\
(19-27)\end{array}$ & 16.57 & $<0.001$ \\
\hline \multirow[b]{2}{*}{ Diagnoses : } & Moderate & Major & Minor & & \\
\hline & $\begin{array}{l}22.8 \pm 2 \\
(18-26)\end{array}$ & $\begin{array}{l}21.9 \pm 2.4 \\
(15-28)\end{array}$ & $\begin{array}{l}21 \pm 2.5 \\
(16-28)\end{array}$ & 29.7 & $<0.001$ \\
\hline
\end{tabular}

Table (7): Correlation matrix among scores of patients' satisfaction factors in New Surgical Hospital at Zagazig University Hospitals:

\begin{tabular}{|c|c|c|c|}
\hline The factors : & $\mathbf{R}$ & $\mathbf{P}$ & \\
\hline Environmental factors: & -0.45 & $<0.001$ & HS * \\
\hline Patient rights factors : & -0.17 & $<0.001$ & $\mathrm{HS} *$ \\
\hline Health education factors & -0.06 & $>0.05$ & NS \\
\hline Performance factors : & -0.11 & $<0.001$ & $\mathrm{HS} *$ \\
\hline Social relation factors : & -0.01 & $>0.05$ & $\mathrm{NS}$ \\
\hline $\begin{array}{l}\text { Patient psychological and } \\
\text { safety factors : }\end{array}$ & -0.4 & $>0.05$ & NS \\
\hline
\end{tabular}

\section{References}

1- Abd-elrhman, A. Assessment of implemented infection control program of nurses in zagazig fever hospital. Unpublished Master Thesis , Zagazig University , Faculty of Nursing , Egypt 2010.

2- Atchison, J. Perceived job satisfaction factors of nursing assistants employed in Midwest nursing home . Retired from : www.Geriatricnurs.gov/morapro7/com.2008

3- Bjork, I., \& Samdal, G. Job satisfaction in a resistance : A study of job satisfaction . Journal of Nursing Management Studies
,2006; 35 ( 3 ) 531- 540 .

4- Coomber, B., \& Barribal, L. Impact of job satisfaction components on the intent to leave and turnout for hospital based nurse. International Journal of Nursing Studies , 44 2007; ( 2 ) $297-314$.

5- El- said, M. Relationship between motivation and job satisfaction among nurses, Zagazig University, Unpublished Master Thesis , Faculty of Nursing, Egypt , 2002;39.

6-El- said, S. Development , implementation and evaluation of an 
educational program for nurses to assure quality care relevant to recording in Surgical wards at zagazig university hospitals . Unpublished Doctorate Thesis, Faculty of Nursing, Zagazig University, Egypt.2002

7-El-said, K.Leadership styles empowerment and job satisfaction among nurses. Ain- Shams University, Unpublished Master Thesis , Faculty of Nursing , Egypt , 2005;83 .

8- El-sebaay, f.Quality improvement in medical units at Aexendria main hospital . Alexendria University, Faculty of Nursing , Unpublished Doctorate Thesis , Egypt .2002 9-Ibrahim, H.Relationship between nurses' job satisfaction and quality of their performance in Abo-Kbier general Hospital - Zagazig university Unpublished Master Thesis, Faculty of Nursing, Egypt. 2009

10-Lu, H., Alison, E., \& Barribal L., (2009): Job satisfaction among nurses: A literature review . International Journal of Nursing studies. Retired from: www. Sciencedirect.com .

11- Lundgren, S., Nordholm, l., \& Sengesten, K . Job satisfaction in relation to change to all RN staffing . Journal of Advanced Nursing ,2005; 13 ( 3 ) 322- 328 .

12- Mohamed, S: Relationship between job satisfaction and absenteeism among nurses . Un-Published Master Thesis , Ain-Shams University , Faculty of Nursing , 2002;10 .

13- Mostafa, H., ( 2004 ) : Leadership styles and job satisfaction among nursing managers and faculty member. Ain- Shams University Hospitals, Upublished Master Thesis, Faculty of Nursing, Egypt .

14- Price, M., ( 2008 ) : Job satisfaction of registered nurses working in an acute hospital . Britishing Journal of Nursing , 11 ( 4 ) 275- 280 .

15- Said, N. Performance effect of first line management functions on productivity of hospital personnel. Unpublished Doctorate Thesis, Zagazig University, Faculty of nursing , Egypt , 2005;69, 72 .

16- Saleh, M.Nurses compliance to standards of nursing care in performing invasive procedures at Zagazig university hospitals . Unpublished Master Thesis, Faculty of nursing, Zagazig university , Egypt 2009

17-Syptak, J., Marsland, D., Ulmer, D.,: Job satisfaction : putting theory into practice . Family practice Management, 2009;6(9) : 18-26.

18- Tantawy, N. Nurses knowledge and practice related to infection control in operating room at Zagazig emergency hospital . Unpublished Master Thesis, Zagazig University, Faculty of Nursing , Egypt 2000; 77- 85 .

19- Tantawy, N: Development of nursing care standards for emergency surgical patients . Unpublished Doctorate Thesis , faculty of Nursing, Ain-Shams University, Egypt .2004

20- Zakaria, A. The effect of communication program on the performance of nurses in surgical units at El- mansoura university hospital . Unpublished Doctorate Thesis, Ain-shams University, Faculty of Nursing, Egypt.2009 